\title{
O Poder Judiciário sob a Perspectiva do Povo como "Instância Global de Atribuição de Legitimidade" e a Nova Sistemática Processual Civil Brasileira de 2015
}

\section{Ciro di Benatti Galvão}

Mestre e especialista em Ciências Jurídico-Políticas pela Faculdade de Direito da Universidade de Lisboa (FDUL). Mestre em Direito do Estado pela Universidade de São Paulo (USP). Bacharel em Direito pela Universidade Federal de Juiz de Fora (UFJF). Professor de Direito Constitucional e Teoria do Estado no Centro Universitário Presidente Tancredo de Almeida Neves (Uniptan). Membro do Conselho Editorial da Revista da Procuradoria Geral do Município de Juiz de Fora. Membro da Academia Barbacenense de Ciências Jurídicas (ABCJ) e do Conselho Editorial da respectiva Revista. dibenatti@yahoo.com.br

\section{Paulo Afonso de Oliveira Junior}

Mestrando em Direito pela Universidade Federal de Ouro Preto (Ufop). Especialista em Direito Internacional pelas Faculdades Milton Campos. Bacharel em Direito pela Universidade Presidente Antônio Carlos (Unipac). Professor e coordenador do curso de Direito da Unipac. Membro da diretoria da Terceira Subseção da OAB/MG (presidente), da Comissão Estadual de Ética e Disciplina da OAB/MG e da Academia Barbacenense de Ciências Jurídicas (ABCJ). pauloafonsodeoliveira@yahoo.com.br

\section{Josilene Nascimento Oliveira}

Bacharel em Direito (2002) e especialista em Direito Civil e Processual Civil pela Unipac (2004). Especialista em Ciências Criminais pela Universidade Estácio de Sá (Unesa). 
Analista do Ministério Público do Estado de Minas Gerais e professora-assistente da Universidade Presidente Antônio Carlos $\square$ Campus Barbacena. josinoliveira@gmail.com

\title{
Resumo
}

0 objetivo do presente artigo é correlacionar a atividade do poder Judiciário e a noção de Müller sobre o povo enquanto "instância de atribuição de legitimidade", abordando a necessidade da intermediação da figura do amicus curiae como entidade responsável pela manutenção do vínculo democrático que deve existir entre eles e que ganhou projeção com a edição do novo Código de Processo Civil brasileiro de 2015. A partir da base compreensiva de que o povo deve ser analisado como verdadeira instância da qual os poderes estatais buscam legitimidade existencial, nada mais coerente que a intervenção social junto a ele se concretize mediante entidades que possam externar a vontade social e/ou seus interesses, quando necessário para a manutenção da legitimidade do comportamento decisório do Judiciário. Adotando-se a pesquisa teórica e valendo-se do método dedutivo, chegou-se à conclusão de que a democratização do comportamento do Judiciário tem como pressuposto a sua contínua integração decisória por entidades técnicas, aptas a suprir a impossibilidade da presença direta dos cidadãos no processo judicial de decisão, na maioria das vezes, garantindo-Ihe maior solidez e maiores chances de legitimidade social.

Palavras-chave: Povo. Friedrich Muller. Amicus curiae. Democratização. Legitimidade.

\section{The Intervention of Amicus Curiae and the New Civil Process Code of 2015: qualified procedural democracy}

\begin{abstract}
The purpose of this article is to correlate the activity of the Judiciary power and Müller's notion about the people as an "instance of attribution of legitimacy", addressing the need for the intermediation of the amicus curiae as entity responsible for maintaining the democratic bond that must exist between them, which has been projected with the edition of the new Brazilian Civil Process Code of 2015. The idea that all manifestation of state power comes from the people, makes it a true instance in which all the constituted powers of the State seek existential legitimacy (after all, the power of the state exists to serve the people, absolute holder of the sovereignty manifested by him). It is from this understanding base that the Judiciary must be analyzed in the exercise of its function and, in the factual impossibility of direct participation of the people in the process of judicial decision, nothing more coherent than the social intervention by entities that can express the same will and/or interest, when necessary to maintain the legitimacy of the Judiciary. Adopting the theoretical research, supported by the deductive method, it was concluded that the democratization of the Judiciary's behavior presupposes its continuous integration by technical entities, able to overcome the impossibility of direct presence of citizens in the decision-making process Judicial, most of the time.
\end{abstract}

Keywords: People. Friedrich Muller. Amicus curiae. Democratization. Legitimacy.

Recebido em: 10/1/2017

Revisões requeridas em: 19/3/2017

Aceito em: 3/4/2017

\section{Sumário}

1 Introdução. 2 A atualidade do pensamento democrático em Müller e seus reflexos na atividade processual do Estado. 3 A atividade judiciária na contemporaneidade. 4 Da importância do amicus curiae para a qualidade decisória do Judiciário no CPC de 2015. 5 Considerações finais. 6 Referências. 


\section{INTRODUÇÃO}

A edição da nova lei, datada de 16 de março de 2015, que regulamenta e disciplina a realidade processual civil brasileira, evidencia não apenas uma nova perspectiva de compreensão da sistemática processual em si, mas a necessidade de se entender, assimilar e oportunizar novos caminhos para a concretização do acesso à Justiça, norma constitucional contida no artigo 5º, XXXV da Constituição Federal de 1988.

Sabe-se que o acesso à Justiça ou à ordem jurídica justa pressupõe não apenas o "direito de ação”, exercitado junto a estrutura judiciária do Estado, com o objetivo de obter uma resposta à pretensão deduzida, mas, presume, principalmente:

a) a viabilidade de participação cidadã e/ou da sociedade civil no próprio processo decisório;

b) a retirada do Judiciário do protagonismo exclusivo no processo de manutenção da coesão social por via da resolução conflitiva de interesses e direitos.

Para o presente trabalho valer-se-á do aproveitamento das duas ideias citadas, mas de maneira a trabalhá-las conjuntamente. Levando-se em conta o contexto sociopolítico atual (plural ou diversificado em sua essência), reconhecer a necessidade de novos atores aptos a contribuir para a realização da norma constitucional do acesso à Justiça ou a potencializar a atividade de atores tradicionais já existentes e vocacionados para tal intento, apresenta-se como uma necessidade de primeira grandeza, de maneira que conceber o Judiciário como o único detentor de legitimidade para cumprir o mandamento constitucional do acesso à Justiça sinaliza uma postura retrógada e destituída de sentido prático. 
A renovação de tal postura far-se-á mediante o estímulo gradativo e contínuo da participação cidadã e da sociedade civil direta ou indiretamente, no processo decisório, colaborando para que haja: 1) maior efetividade na solução jurídica para problemas sociais judicializados; 2) maior qualidade técnica das soluções jurídicas.

A busca por mecanismos ou figuras inovadoras que estejam amparados em termos de compreensão, assimilação e anuência social sobre a decisão a ser aplicada, tem se tornado um desafio para a estrutura judiciária estatal, de maneira que, atualmente, se não forem pensadas formas integrativas e verdadeiramente qualitativas em termos de resolução conflitiva, a própria existência de direitos ficará comprometida.

De fato, o direito ao acesso efetivo tem sido progressivamente reconhecido como sendo de importância capital entre os novos direitos individuais e sociais, uma vez que a titularidade de direitos é destituida de sentido, na ausência de mecanismos para sua efetiva reivindicação. $\mathrm{O}$ acesso à justiça pode, portanto, ser encarado como o requisito fundamental - o mais básico dos direitos humanos - de um sistema jurídico moderno e igualitário que pretende garantir, e não apenas proclamar os direitos de todos (CAPPELLETTI; GARTH, 2002, itálico nosso).

Nesse sentido, e levando-se em consideração os objetivos pretendidos pela nova lei processual civil de 2015 que, desde o seu anteprojeto, persiste na permanente constitucionalização do processo, relendo-o e realizando-o a partir de orientações constitucionais (como a norma do acesso à Justiça), tornando-o um instrumento facilitador e apto a gerar resultados mais eficientes ${ }^{1}$ em termos de resolução de questões sociais, problematizadas em processos judiciais, é que será tratada a atividade decisória do Judiciário, de maneira que ele abranja, na maior medida possível, a inter-

${ }^{1}$ Em sentido semelhante, cf. Wambier et al. (2015, p. 51). 
venção social em seus processos de tomadas de decisão, absorvendo os inputs necessários a formalizar a suas convicções decisórias de maneira mais acertada e coerente.

A tendência finalística em termos de realização adequada e qualitativa de direitos dos cidadãos e da sociedade ficou evidenciada na seguinte passagem da exposição de motivos do anteprojeto:

Um sistema processual civil que não proporcione à sociedade o reconhecimento e a realização dos direitos, ameaçados ou violados, que têm cada um dos jurisdicionados, não se harmoniza com as garantias constitucionais de um Estado Democrático de Direito (BRASIL, 2010)

Entre os atores que diretamente estão atrelados à observância dessa norma originariamente constitucional, está o poder Judiciário. Sobre isso não restam dúvidas, contudo os desafios que lhe são colocados e que têm direta proximidade com a temática do acesso à Justiça forçam o comportamento deste poder estatal a não apenas resolvê-los (quando esses desafios se tornarem problemas palpáveis e judicializados), mas solucioná-los adequadamente de maneira a ressignificar a ideia de prestação jurisdicional. Nesse sentido, pode-se afirmar que quanto mais participado o processo for, maior será o potencial de eficácia e, por consequência, maior será a legitimidade social referente ao comportamento decisório tomado.

Tal pensamento é respaldado no pensamento a seguir extraído de Mauro Cappelletti, em que o autor explicita a renovação da compreensão de acesso à Justiça mediante o incentivo a novas formas de concretização de seu significado:

submeter a atividade pública a formas, muitas vezes novas e de qualquer modo mais alargadas e acessiveis, de controle; e, em geral, de criar formas de justiça mais acessiveis enquanto mais descentralizadas e "participativas", com a presença, em particular, dos membros desses mesmos grupos sociais e comunidades que estão diretamente envolvidos na situação ou controvérsia. É precisamente pelo surgimento desta última 
finalidade que um dos temas de maior interesse teórico e prático apareceu recentemente na participação de leigos na administração da justiça (2008, p. 6, itálico nosso).

A figura do amicus curiae insere-se no cenário de tratamento da questão exposta anteriormente, ou seja, a sua adoção, como interveniente decisório, representa uma maior abertura ou sensibilidade decisória do Judiciário, de maneira que, mediante a sua incidência, o processo decisório torna-se mais participado, contribuindo para o aumento da qualidade técnica de suas decisões, fazendo com que elas sejam mais bem assimiladas como válidas pelo contexto social. E mais: a sua utilização como instrumento técnico de decisão acaba por fazer com que a atividade do Judiciário corresponda ao pensamento de Müller sobre o povo como um locus de legitimidade estatal ao qual a estrutura estatal deve recorrer para que se tenha uma real construção do sentido de democracia.

Dessa forma, para desenvolver esse tema, o presente texto tratará, em um primeiro momento, da exposição e explanação da base teórica que sustentará a hipótese para a problemática suscitada pelo tema, referente à necessidade de tornar a atividade do poder Judiciário mais consentânea com o ideal constitucional de acesso à Justiça. Para tanto, será trabalhada a perspectiva de Müller do povo como "instância global de atribuição de legitimidade estatal”, de maneira a proporcionar que essa estrutura funcional do Estado torne-se mais sensível e aberta à participação da sociedade civil, quando viável e necessário em termos de instrução técnica. Na segunda parte do texto apresentar-se-á a função judiciária ou a atividade judiciária na contemporaneidade, confrontando-a com o ideal crescente de democratização e abertura decisória. Na terceira parte será abordada a figura do amicus curiae e de sua importância para o iter de elaboração das decisões do poder Judiciário em um contexto em que os desafios sociais que são judicializados acabam demandando certos know-how ou expertise específicos, expondo as fragilidades técnicas da estrutura judiciária estatal. Nesse 
momento será traçada a correlação entre as duas partes para, ao final, chegar-se à conclusão de que a intervenção dos amici curiae tem grande potencial para proporcionar maior aperfeiçoamento à atividade judicial, contribuindo para o aumento da legitimidade do próprio Estado, posto que o ideal de fomento à intervenção da sociedade no comportamento estatal (e, portanto, o fomento à abertura estatal à democracia) será possibilitado mediante $o$ intermédio dessas figuras processuais.

\section{A ATUALIDADE DO PENSAMENTO DEMOCRÁTICO EM MÜLLER E SEUS REFLEXOS NA ATIVIDADE PROCESSUAL DO ESTADO}

Felizmente, o debate acerca do real papel da jurisdição, associando-a ao campo próprio da democracia, tem ganhado ressonância e projeção, forçando a superação de pensamentos retrógados e descompassados da realidade circundante, que eventualmente ainda possam existir quando se está a analisar a questão da atuação do poder Judiciário. A atividade processual, hoje, deve abarcar e trabalhar os inputs sociais no seu próprio desenvolvimento, ou seja, durante o seu iter decisório, sempre que eles puderem impactar positivamente na qualidade da decisão final; disso não resta dúvida.

Eduardo Cambi (2011, p. 373) ressalta o escopo político do processo ou da atividade processual ao sobrelevar a participação dos cidadãos na discussão das questões públicas, afirmando que ela - participação social apresenta-se como mecanismo significativo em termos republicanos e de promoção da democracia, favorecendo o controle do poder político estatal, mediante a explicitação do exercício da própria cidadania.

A democratização da administração da Justiça tem se tornado, portanto, assunto cuja importância deve ser absorvida gradativamente pelo Estado e por sua estrutura. Para tanto, a compreensão do povo, na 
condição de categoria essencial para o pensamento democrático, precisa ser tratada para, posteriormente, aplicá-la à teoria da atividade processual do Estado.

A partir de um viés procedimental, a democracia é considerada por Norberto Bobbio (2006, p. 18) o único modo de se obter um acordo contrário a todas as formas autocráticas de governo, sendo caracterizada "por um conjunto de regras que estabelecem quem está autorizado a tomar as decisões coletivas e com quais procedimentos”.

Todo este discurso apenas vale se nos atermos àquela que chamei de definição mínima de democracia, segundo a qual por regime democrático entende-se primariamente um conjunto de regras de procedimento para a formação de decisões coletivas, em que está prevista e facilitada a participação mais ampla possível dos interessados. Sei bem que tal definição procedimental, ou formal, ou, em sentido pejorativo, formalística, parece muito pobre para os movimentos que se proclamam de esquerda. Porém, a verdade é que não existe outra definição igualmente clara e esta é a única capaz de nos oferecer um critério infalível para introduzir uma primeira grande distinção (independentemente de qualquer juízo de valor) entre dois tipos ideais opostos de formas de governo (p. 12, itálico nosso).

No mesmo sentido posiciona-se Schumpeter (1984) ao compreendê-la como método. Na visão do autor, para a concretização do pensamento democrático são vitais a aceitação e o respeito a certas regras, que são pressupostas a sua existência.

Embora, contudo, seja reconhecida a importância da questão procedimental, (relacionada às regras ou condições formais adotadas pelo sistema democrático, em especial, o instituto da representação política - mediante o exercício do direito fundamental do voto em certames eleitorais), a questão democrática não pode ser resumida, apenas, a esse aspecto formal. 
Iris Marion Young (2006, p. 139-140), ao se reportar às chamadas sociedades fluidas e de massas, questiona a pertinência da abordagem da representatividade democrática pelo voto, salientando que são frequentes as queixas de certos núcleos sociais para o caráter excludente das normas de representação tradicionais. Uma vez que "uma democracia forte certamente requer diversas ocasiões em que autoridades públicas e cidadãos se encontrem para discutir determinadas experiências e questões”, torna-se crucial, portanto, repensar os vínculos jurídicos entre cidadão e Estado, tornando mais palpável o significado de democracia a ser experimentado pelas funções estatais.

Justamente por não poder ser tida como um mero método político, desacoplado ou desconectado das decisões que serão tomadas por seu intermédio, a democracia faz crer que a decisão, em si, e tomada em seu nome, mereça refletir, na prática, os interesses daqueles afetados por elas. Reflexão que, é sabido, deve ser oportunizada por uma maior abertura à real participação social, conforme prudentemente observado por Sabrina Carvalho (2016, p. 30) ao expor que um dos traços caracterizantes do Estado Democrático de Direito está na “condicionante de legitimidade das decisões estatais, que necessariamente deve ser pautada na titularidade da força transformadora do povo”, mostrando-se imprescindível a fiscalização da eficácia e da legitimidade dos instrumentos utilizados no exercício de gestão pública, com o escopo de se identificar, verdadeiramente, se esses instrumentos são frutos de determinada constituição social (CARVALHO, 2016, p. 30-31).

Nesse sentido, portanto, apresenta-se pertinente o tratamento da questão do povo a partir do pensamento de Friedrich Müller na obra intitulada Quem é o povo? (2013), ao ressaltar a necessidade de estabelecimento de verdadeiros vínculos jurídicos entre ele (povo) e o Estado para que a sua conceituação e compreensão se aperfeiçoem, especialmente a partir do seu enquadramento como verdadeira "instância global de atribuição 
de legitimidade” (p. 59), de maneira que a participação social possa ser viabilizada em todos os comportamentos decisórios do Estado, por meio de cada um dos seus poderes constituídos.

A perspectiva procedimental é tratada por Müller ao expor a ideia de "povo ativo", entendido por ele como o povo que exerce a sua dominação por intermédio de "instâncias de autogestão" eleitas para que sejam criadas ou executadas prescrições jurídicas (2013, p. 51), ou seja, o povo ativo realiza-se a partir da noção de representatividade política dos que corporificam a condição de nacional eleitor.

Conforme exposto por Müller (2013, p. 53), no entanto, “o povo ativo [referindo-se ao conjunto de nacionais com capacidade para exercer os direitos políticos] não pode sustentar sozinho um sistema tão repleto de pressupostos”, como o é a democracia, dado que a limitação imposta pela representação política, mediante o voto, pode conduzir a processos gradativos de exclusão ou marginalização social, contrariando ideais próprios de Estado de Direito e restringindo toda a coerente sistemática de sua compreensão (p. 52-53).

É perceptível, pois, que a atividade estatal, em contextos de Direito, deve justificar-se pela consideração de todos os interessados que, de certa maneira, possam ser atingidos pelo seu comportamento decisório, não sendo permitido que haja um direcionamento de sua atividade apenas aos que tenham reconhecida a capacidade eleitoral plena (em razão da nacionalidade) e participado, pontualmente, de certames eleitorais mediante o voto que, conforme observado por Pierre Rosanvallon (2006, p. 232), é certamente a forma mais visível e institucionalizada da cidadania, simbolizando a noção de participação política e igualdade cívicas mas que, por sua vez, devem tornar-se expressões mais complexas, devendo combinar ou aliar três dimensões de interação entre o povo e a esfera política: a expressão, a implicação e a intervenção. 
A essa última manifestação ou dimensão (intervenção) tratada por Rosanvallon associa-se o pensamento de Müller ao propor uma perspectiva complementar a respeito do "povo”, concluindo, com relação ao "povo ativo", que toda forma de representatividade [política] elimina a imediatidade (MÜLLER, 2013, p. 53). Em oposição a sua colocação como objeto de dominação, Müller passou a se referir a ele [povo] como locus ou estrutura da qual deriva toda a legitimidade estatal, independentemente da tradicional representação política (própria da classificação como "povo ativo") e que deve se fazer presente ou influenciar, gradativamente, e na medida do possível, todos os processos cotidianos de decisão no contexto estatal. Trata-se de perspectiva que se justifica para atribuir maior sentido à tradicional noção de "povo ativo”, que foi (e continua sendo) incapaz de evitar a crescente crise de representatividade política e suas falhas correspondentes.

Embora pressuponha a atuação pretérita do "povo ativo", ${ }^{2}$ a perspectiva do povo como "instância global de atribuição de legitimidade" atribui-lhe, no entanto, uma propulsão maior, pois, apesar de garantidos e exercidos os direitos políticos, não se tem a certeza plena de que as orientações normativas tomadas pelos representantes políticos eleitos irão influenciar (mesmo que indiretamente) o comportamento dos demais poderes constituídos do Estado, forçando a adequação da atividade de cada um deles a essas mesmas orientações legais previamente estabelecidas pelos representantes dos cidadãos-eleitores (MÜLLER, 2013, p. 55).

${ }^{2}$ Müller é enfático ao argumentar, nesse sentido, que o povo enquanto instância de legitimidade somente é defensável em um contexto simultâneo de valorização da vertente de povo ativo, não sendo possível a sua existência em contextos autoritários, no qual o povo é invocado fartamente como fator de legitimidade em um primeiro momento, tendo, posteriormente, “(des)valor ideológico, não mais função jurídica” (2013, p. 58). 
A perspectiva do povo como instância ou estrutura de legitimidade (por mais ampla que possa ser considerada tal figura alegórica) faz com que os membros da sociedade estabeleçam com o Estado um novo vínculo jurídico, levando-se em conta, por exemplo, o fundamento ou base normativa prevista no conteúdo do artigo $1^{\circ}$, parágrafo único do Texto Constitucional de 1988, de maneira que tal determinação normativa seja assimilada pelos órgãos estatais, forçando-os a exercerem as respectivas funções em sintonia com ela.

Para tanto, canais efetivos de participação e intervenção social devem ser oportunizados por esses mesmos órgãos e poderes ao contexto social prático, de maneira a explicitar a abertura democrática do próprio Estado, de modo a torná-la (democracia) objeto de deliberação na própria estrutura funcional do Estado. Com isso, aumenta-se não apenas a legitimidade de seu comportamento, como passa a ser mais frequente a exigência de que haja maior retidão e coerência comportamental por parte do Estado em si, mediante a atuação de seus poderes.

A admissão de métodos e ferramentas que apresentam proximidade com tais ideais e que se mostrem hábeis a aperfeiçoar o exercício das funções estatais (inclusive a função judiciária) faz com seja defendido o argumento referente à necessidade de possibilitar, na maior medida possível, a utilização de instrumentos de intervenção da própria sociedade civil, como forma de potencializar os ganhos qualitativos das decisões a serem tomadas, reforçando ideais democráticos, especialmente em demandas de massa em que a complexidade do conteúdo discutido ganha projeção, tendo reflexos no próprio âmbito social, justificando-se a presença de entidades detentoras de adequada representatividade social, auxiliando na construção ou elaboração da decisão final. 
Tal abertura à participação faz com que novos contornos semânticos sejam atribuídos ao pensamento democrático, cuja compreensão vai além da visão procedimental/formal, ganhando contornos práticos mediante colaboração da própria sociedade civil, conforme prudentemente observado por Robert Alexy na seguinte passagem:

A democracia é o elemento mais importante no lado procedimental da institucionalização da razão. A democracia pode ser concebida, ao mesmo tempo, como um procedimento de decisão e como um procedimento de argumentação. A decisão na linha do princípio da maioria, é o lado real da democracia. A argumentação, como discurso público, é o lado ideal. A única possibilidade para a realização dos ideais da teoria do discurso é a institucionalização de uma democracia que una ambos os lados. O nome dessa unidade é "democracia deliberativa” (2014, p. 217, itálico nosso).

A sensibilidade a esse pensamento, por exemplo, torna as estruturas de decisão do Estado menos herméticas e mais inclusivas, sobrelevando, de maneira responsável, a importância e a necessidade de se inserir a sociedade nos seus processos formais de tomadas de decisão, favorecendo a subsidiariedade da administração da Justiça sob a tutela responsável dos ditames legais, garantindo-se, ao final, maiores índices de decisão mais bem elaboradas e condizentes, de maneira que se tornam mais fáceis de serem absorvidas socialmente como decisões válidas.

Percebe-se, assim, que há nítida relação entre o pensamento de Alexy e a proposta estruturante de Müller sobre o povo como "instância de atribuição de legitimidade”, pois será a assimilação da necessidade de participação efetiva do povo nos processos decisórios do Estado que fará com que a proposta de democracia argumentativa salientada por Alexy possa se concretizar. Não há como os processos decisórios (entre eles o processo de decisão judicial) absorverem a carga argumentativa em termos democráticos se canais para que ela (vontade social) se manifeste não sejam criados ou estimulados. 
É nesse contexto que a atuação do amicus curiae será abordada a seguir, adiantando-se o pensamento de que ele concretiza a virtude democrática trabalhada por Müller, podendo-se entendê-lo como entidade que atribui maior índice de legitimidade funcional ao poder Judiciário.

\section{A ATIVIDADE JUDICIÁRIA NA CONTEMPORANEIDADE}

Não me importa o que pensam os doutrinadores. Enquanto for ministro do Superior Tribunal de Justiça, assumo a autoridade da minha jurisdição. O pensamento daqueles que não são ministros deste Tribunal importa como orientação. A eles, porém, não me submeto. Interessa conhecer a doutrina de Barbosa Moreira ou Athos Carneiro. Decido, porém, conforme minha consciência. Precisamos estabelecer nossa autonomia intelectual, para que este Tribunal seja respeitado. É preciso consolidar o entendimento de que os Srs. Ministros Francisco Peçanha Martins e Humberto Gomes de Barros decidem assim, porque pensam assim. E o STJ decide assim, porque a maioria de seus integrantes pensa como esses ministros. Esse é o pensamento do Superior Tribunal de Justiça e a doutrina que se amolde a ele. É fundamental expressarmos o que somos. Ninguém nos dá lições. Não somos aprendizes de ninguém. Quando viemos para este Tribunal, corajosamente assumimos a declaração de que temos notável saber jurídico - uma imposição da Constituição Federal. Pode não ser verdade. Em relação a mim, certamente, não é, mas, para efeitos constitucionais, minha investidura obriga-me a pensar que assim seja (BRASIL, STJ. AgRg nos Eresp 319.997-SC, Relator: Min. Peçanha Martins, DJ 7/4/2003, p. 216, itálico nosso).

O trecho citado é um fragmento do voto do ministro Orlando Gomes de Barros, do Superior Tribunal de Justifica (STJ), extraído da análise e do julgamento de uma ação processual cuja relatoria coube ao ministro Peçanha Martins. Causa estranheza (para dizer o mínimo) a sua leitura, reveladora de certo autismo decisório e de aversão à participação externa no ato de elaboração do raciocínio decisório de um servi- 
dor público da magistratura nacional, componente de uma das principais estruturas decisórias do país. A verdade, no entanto, é que esse tem sido um comportamento frequente na seara do poder Judiciário brasileiro, revelando a problemática do presente texto, relacionada à atribuição de legitimidade às decisões judiciais na atualidade brasileira mediante a participação democrática.

Diante do cenário exposto, como atribuir legitimidade a uma decisão tomada nestes termos? Como reconhecê-la como prudente, coerente e realmente conformadora, se se evidencia que a sua existência teve por base, exclusivamente, a absoluta autonomia individual (nem se está a falar de autonomia funcional, frise-se!) de quem a decidiu? E, se se tratasse de uma ação processual complexa, indaga-se: Como pensar na viabilidade da intervenção técnica externa, levando-se em consideração o isolacionismo decisório explicitado no voto do referido ministro neste processo?

O papel exercido pela jurisdição, hoje, está no direcionamento de seu olhar para o aperfeiçoamento dos sistemas judiciais, de forma a torná-los críveis, verossímeis perante a sociedade. Afinal, a busca pela assimilação social é (e continuará sendo) necessária para a sustentabilidade de qualquer decisão do Estado. É nisso que está parcela de sua legitimidade na condição de ente responsável direta ou indiretamente pela ordenação ou organização de determinado núcleo social.

A rediscussão das bases democráticas das instituições e dos poderes constituídos do Estado, particularmente do poder Judiciário, é uma temática constante, permanente. Principalmente, levando-se em consideração o fato de que os seus membros são destituídos de legitimidade democrática direta (decorrente do voto) tal como ocorre com os que compõem os dois outros poderes constituídos do Estado (Legislativo e Executivo). Nem por isso, contudo, trata-se de um poder avesso às pretensões relacionadas à cidadania, à valorização, à defesa e, ainda, ao aperfeiçoamento da democracia. 
Em razão das pretensões do constitucionalismo democrático, não há razão que possa justificar a isenção ou inexistência de enquadramento democrático à função jurisdicional do Estado. Conforme prudentemente observado por Flávia Piovesan (2000, p. 102), a democracia não se vincula ou se limita, tão somente, ao modo ou procedimento formal pelo qual o poder político é exercido, pressupondo e envolvendo, fundamentalmente, a forma pela qual os direitos são efetivados.

Nesse sentido, afirma-se que o papel da jurisdição, em Estados de Direito, não é, apenas, solucionar demandas decorrentes de conflito de direitos ou interesses, mas resolvê-las adequadamente, expressando, de certa maneira, o compromisso institucional com o alcance do real e qualitativo acesso à Justiça ao analisar direitos ou interesses levados à deliberação decisória perante a estrutura judiciária do Estado. A credibilidade do poder Judiciário reside, em sua essência, nisso.

Dessa forma, oportunizar formas instrumentais que evidenciem esse comprometimento com a qualidade do exercício da função jurisdicional é comprometer-se democraticamente, já que estar-se-á a analisar situações conflituosas relacionadas a direitos dos cidadãos, individual ou coletivamente considerados e que carecem de boa resolução. A busca pela qualidade da tutela jurisdicional diz muito sobre a existência ou não de inclinação democrática de um Estado.

Visa-se com isso a expor o raciocínio de que a relação entre democracia e qualidade prestacional de tutela jurisdicional é diretamente proporcional, de maneira que se a resposta jurisdicional for destituída de qualidade técnica suficiente sofrerá, no final, o próprio cidadão, que passará a desconfiar (ainda mais, diga-se de passagem) da capacidade de um dos poderes do Estado em auxiliá-lo a manter ou cumprir a sua meta constante, relacionada à organização ou coesão social. A frustação com a qualidade de uma decisão judicial, quando evidenciada qualquer falha em sua elaboração, afetando diretamente ou não algum direito ou interesse legítimo 
do cidadão, faz nascer nele a desconfiança no próprio comprometimento estatal para consigo, podendo ocorrer, a partir disso, um efeito cascata em termos sociais.

Dessa forma, chega-se ao raciocínio de que o poder responsável pela prestação jurisdicional, em tempos atuais, para poder exercer bem a sua função, preocupando-se com a qualidade de suas decisões para a resolução de determinado aspecto da vida do cidadão deve, para o alcance de maior grau qualitativo, permitir-se influenciar por argumentos técnicos necessários que tragam maior respaldo à decisão, garantindo-lhe menores chances de desconfiança por parte dos que forem direta ou indiretamente afetados, fortalecendo, ainda, o grau de legitimidade social do próprio Estado.

Calmon de Passos (1988, p. 95), referindo-se ao processo, em sede da realidade brasileira, já apontava para essas questões ao trazer reflexões sobre a necessidade de se democratizar a atividade processual perante o poder Judiciário, afirmando que ela caminha para o seu enquadramento como “instrumento político de participação”, de maneira que havendo a democratização do Estado, o processo acabou sendo alçado à "condição de garantia constitucional" e a democratização da sociedade fez [e faz] dele instrumento de atuação política. Por seu intermédio, é cumprido o papel tradicionalmente conhecido de garantia e proteção, mas, igualmente, deve-se migrar para uma atuação complementar, referente à necessidade de se garantir, por intermédio da atividade processual, a efetivação de "objetivos politicamente definidos pela comunidade” (CALMON DE PASSOS, 1988, p. 95).

Sabendo-se que, constitucionalmente, os objetivos do Estado brasileiro referem-se, por exemplo, à promoção do desenvolvimento nacional, bem como à construção de uma sociedade amparada nos ideais de liberdade, justiça e solidariedade, além do estímulo ao combate à marginalização e, ainda, o estímulo à promoção do bem-estar em seu sentido mais amplo (vide artigo $3^{\circ}$ da Constituição Federal de 1988), quando se estiver diante da possiblidade de se alcançar tais desideratos - relevantes em termos comunitários - por meio da atividade processual, tal perspectiva sobre ela deve ser estimulada a ocorrer. 
Entendidas como derivações do gênero decisão estatal, as decisões judiciais prolatadas processualmente podem acabar tendo reflexos para além das partes envolvidas, em muitas situações, alcançando bens e interesses comunitários, originalmente não participantes da relação processual formalizada, comprometendo metas constitucionalmente fixadas, não havendo razão ou justificativa que impeça que canais participativos, em termos decisórios, sejam, sim, sobrelevados em termos processuais com o nítido escopo de, secundariamente, preservar o acervo teleológico constitucionalmente preestabelecido.

A figura técnica do amicus curiae presta-se a esse intento, conforme será visto em seguida, de maneira que se associa a essa figura interventiva-processual a aplicação do pensamento democrático em Müller ao resgatar e reafirmar o raciocínio de que o povo, até então simbolicamente representado, deve concretizar-se de modo que se evite que a questão democrática seja tratada de maneira utópica, adentrando no campo visual ou real (MÜLLER, 2013, p. 47).

\section{DA IMPORTÂNCIA DO AMICUS CURIAE PARA A QUALIDADE DECISÓRIA DO JUDICIÁRIO NO CPC DE 2015}

Em termos linguísticos, é da expressão latina que significa "amigo da corte"3 ou "amigo do tribunal", que surge, no cenário do Direito Processual, a figura jurídica do amicus curiae, e, em termos de contextuais, a referida figura ganhou projeção com o sistema de common law, a exemplo do Direito inglês e norte-americano.

3 Prudentemente observa Scarpinella Bueno (2011, p. 113) que não se deve preocupar em traduzir a expressão para que se possa compreender o seu significado, pois a ideia de "amigo" pode comprometer a imparcialidade do auxílio técnico-argumentativo trazido pela atuação desta espécie de intervenção de terceiro. 
A partir do modelo de stare decisis (precedentes vinculantes), pelo qual as decisões jurisprudenciais passaram a vincular casos semelhantes que pudessem ocorrer no futuro, estabeleceu-se o raciocínio de que os precedentes judiciais, mediante sua força vinculatória, produziam reflexos em situações futuras semelhantes e de mesma natureza, fazendo surgir a necessidade de se possibilitar a setores sociais diversificados impactar ou influenciar nas decisões judiciais, mesmo que não possuíssem interesse ou relação direta com o objeto do processo em que se manifestavam, conforme bem observado por Cabral (2003, p. 114). Tal modelo interventivo, entretanto, passou a ser plenamente admissível em realidades de civil law, conforme observado por Wambier et al. (2015, p. 256).

O ordenamento jurídico brasileiro já fazia menção a ele, conforme pode ser verificado na análise do artigo $7^{\circ}$, $\S 2^{\circ}$, da Lei $9.868 / 99$; artigo 14 , § $7^{\circ}$, da Lei $10.259 / 2001$, e no artigo $3^{\circ}$, $\S 2^{\circ}$, da Lei $11.417 / 2006$, que tratam da edição, revisão e/ou cancelamento das súmulas vinculantes do Supremo Tribunal Federal. Atualmente, a partir da edição da nova lei processual civil de 2015, há previsão expressa à figura do amicus curiae, algo inédito na realidade jurídica brasileira que, até então, fazia menção a sua existência em legislações específicas, conforme visto anteriormente, dando margem à interpretação de que a sua incidência processual somente se daria em situações processuais excepcionais, legalmente prefixadas ou preestabelecidas. Hoje, a sua incidência como terceiro interventivo é cabível em qualquer contexto processual, desde que haja o atendimento ao comando normativo previsto no artigo 138 do NCPC, que assim dispõe:

O juiz ou o relator, considerando a relevância da matéria, a especificidade do tema objeto da demanda ou a repercussão social da controvérsia, poderá, por decisão irrecorrível, de ofício ou a requerimento das partes ou de quem pretenda manifestar-se, solicitar ou admitir a manifestação de pessoa natural ou jurídica, órgão ou entidade especializada, com representatividade adequada, no prazo de quinze dias da sua intimação (BRASIL, 2015, itálico nosso). 
A partir da edição do Novo Código de Processo Civil - NCPC, de 2015, a definiç̧ão da sua natureza jurídica restou clara, até mesmo em termos de construção topográfica da Lei, que o inseriu no título III intitulado "Da Intervenção de Terceiros". Dessa forma, fica entendido o amicus curiae como verdadeira forma de "intervenção de terceiro" processual.

Trata-se de pessoa ou entidade inicialmente "estranha" a determinado processo e que, demonstrando interesse na causa (representando segmentos sociais que se apresentam melhor mediante a sua intervenção), por meio de provocação ou voluntariamente, é incluída na deliberação processual, levando-se em consideração a complexidade, a especificidade e/ ou a relevância de certas matérias debatidas, agindo, assim, com o propósito de auxiliar o juiz ou o tribunal, ofertando-lhe esclarecimentos técnicos sobre questões ou assuntos essenciais, à boa resolução do processo em

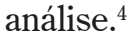

Ele, o amicus curiae, tem que ser entendido como um adequado "representante" destes interesses que existem, queiramos ou não, na sociedade e no Estado ("fora do processo", portanto), mas que serão afetados, em alguma medida, pela decisão a ser tomada "dentro do processo". O amicus, neste sentido, atua em juízo em prol destes "interesses" e é por isto mesmo que, na minha opinião, sua admissão em juízo depende sempre e em qualquer caso da comprovação de que ele, amicus, apresenta-se no plano material (isto é: "fora do processo") como um “adequado representante destes interesses (BUENO, 2011, p. 114).

O que enseja a intervenção deste "terceiro" no processo, conforme observado por Cassio Scarpinella Bueno (2010, p. 162), é a circunstância de ser ele, desde o plano material, um legítimo portador de certo "inte-

4 Em sentido semelhante, cf. Sabrina Carvalho (2016, p. 255) ao ressaltar o valor democrático trazido pela atuação desta figura processual interventiva, que represente 0 que a autora denomina de espécie de potência pública. 
resse institucional"5 (entendido como o que ultrapassa a esfera jurídica de um indivíduo e que, por isso mesmo, é um interesse meta-individual, típico de uma sociedade pluralista e democrática), "que é titularizado por grupos ou por segmentos sociais mais ou menos bem definidos”, merecendo, assim, se posicionar ou se manifestar, participando do chamado contraditório deliberativo.

O amicus curiae não atua, assim, em prol de um indivíduo ou uma pessoa, como faz o assistente, em prol de um direito de alguém. Ele atua em prol de um interesse, que pode, até mesmo, não ser titularizado por ninguém, embora seja compartilhado difusa ou coletivamente por um grupo de pessoas e que tende a ser afetado pelo que vier a ser decidido no processo. O chamado "interesse institucional" autoriza o ingresso do amicus curiae em processo alheio para que a decisão a ser proferida leve em consideração as informações disponíveis sobre os impactos do que será decidido perante aqueles grupos, que estão fora do processo e que, pela intervenção aqui discutida, conseguem dele participar (BUENO, 2010, p. 162).

Em razão da complexidade do "mundo da vida" (para usar a expressão habermasiana) a que tanto o Estado, os seus poderes e a própria sociedade por eles organizada estão submetidos, a questão nevrálgica que se coloca em termos processuais, hoje, refere-se à qualidade e à precisão da decisão judicial, sem se desconsiderar, obviamente, a forte tendência de expansão (mesmo que não diretamente desejada) dos efeitos decisórios para além das partes originalmente envolvidas.

Uma ação processual pode ser - é sabido - simples, mas, em muitas situações, é trazida para o cenário deliberativo-processual uma carga considerável de desafios que forçam a existência de uma correspondente carga analítico-decisória, muitas vezes não apresentada pelo juiz que conduzirá o desfecho do processo em si. Em muitas situações, certas informações ou

5 No mesmo sentido, cf. Wambier et al. (2015, p. 256-257). 
dados - representativos de um know-how específico - mostram-se cruciais para a obtenção da qualidade decisória final de maneira que devem ser inseridas no iter deliberativo-processual, com o nítido escopo de, verdadeiramente, contribuir para a qualidade prestacional em termos processuais e que, desde a promulgação da Constituição de 1988, é entendido como direito fundamental.

A partir disso, conforme observado por Wambier et al. (2015, p. 257), pode-se afirmar que a figura do amicus curiae é utilizada para fazer com que a prática processual civil abarque e concretize valores e determinações constitucionalmente encampados a partir de 1988. Trata-se, pois, de entidade detentora de justificada ou amparo constitucional.

Em termos funcionais ou finalísticos, a figura interventiva do amicus curiae é caracterizada pela sua capacidade de potencializar a deliberação endoprocessual, mediante o fornecimento de dados ou informações técnicas relevantes para a construção do raciocínio do magistrado antes da tomada de decisão judicial e que merecem ser expostas em debate, justamente por que a decisão final poderá repercutir (positiva ou negativamente) externamente às partes propriamente ditas. ${ }^{6}$ Prudentemente, manifesta-se, nesse sentido, o professor Cassio Scarpinella Bueno ao afirmar que:

Ele atua, no melhor sentido do fiscal da lei, como um elemento que, ao assegurar a imparcialidade do magistrado por manter a indispensável terzietà do juiz com o fato ou o contexto a ser julgado, municia-o com os elementos mais importantes e relevantes para o proferimento de uma

${ }_{6}$ Em sentido semelhante, expõe Víctor Bazán (2010, p. 126) que: "la participación procesal del amicus curiae supone la presentación en un proceso de un tercero que interviene aportando una opinión fundada que puede resultar relevante para la resolución de un litigio en el que se debatan cuestiones socialmente sensibles”. 
decisão ótima que, repito, de uma forma ou de outra atingirá interesses que não estão direta e pessoalmente colocados (e, por isto mesmo, defendidos) em juízo (2008, p. 136).

A partir do raciocínio de Dierle Nunes e Alexandre Bahia (2010, p. 62) de que o campo processual suscita maiores digressões diante do fenômeno da judicialização de inúmeras temáticas, tendo a atividade processual, muitas vezes, um papel de promoção de uma jurisdição com função contramajoritária, servindo, ainda, como espaço institucional para aqueles que não conseguem ser ouvidos nas arenas institucionais majoritárias (Parlamento e Executivo), resta evidente a ligação entre o pensamento dos autores e a necessidade de que a própria estrutura funcional judiciária valha-se, gradativamente, de institutos ou mecanismos de aperfeiçoamento da tutela jurisdicional, proporcionando acesso à deliberação processual a segmentos da sociedade civil muitas vezes inaudíveis na exposição de argumentos sobre questões que tocam diretamente as suas esferas de direito e que, eventualmente, estejam sendo debatidas em certa relação jurídica processual.

Pensemos em situações processuais em que indiretamente a decisão judicial atinja algum aspecto crucial da personalidade ou da liberdade de determinado núcleo de indivíduos que originariamente não pertençam à deliberação processual e que não tiveram representatividade democrática direta no Legislativo ou no Executivo para tutelar ou aperfeiçoar algum aspecto significativo de sua vida. Se se estiver diante de uma situação como essa, passível de ser minimamente contornada em uma concreta ação processual, será que não seria desejável atribuir à estrutura judiciária competente a possibilidade de deliberar a contento, a partir de instrumentos adequados, tal aspecto contramajoritário?

Nesse sentido, se a própria estrutura judiciária, no exercício de sua função, não detiver instrumentos auxiliares decisórios tecnicamente aptos, a violação ou comprometimento das esferas de direitos de certa 
parcela da sociedade poderá ser inevitável. Acredita-se que, em conformidade com Iris Marion Young, ${ }^{7}$ oportunizar mais inclusão e influência decisória a núcleos sociais sub-representados, por meio de instrumentos processuais como o amicus curiae, possa contribuir para reduzir o que a autora denomina de "desigualdade social estrutural". Tal sensibilidade foi, felizmente, captada pela nova legislação processual civil brasileira, de maneira que o disciplinamento desta figura processual interventiva fortalecerá a própria função judiciária estatal, contribuindo mais, nos casos em que ela atuar, para a proximidade entre a estrutura e organização estatal e a própria sociedade civil.

\section{CONSIDERAÇÕES FINAIS}

A nova sistemática processual civil adotada pela ordem brasileira em 2015 sobreleva o papel do amicus curiae como forma de intervenção de terceiro, legalmente prevista e passível de ser adotada em todas as relações processuais, conforme depreendido da leitura do artigo 138 do NCPC.

A sua importância, na atualidade, está justamente no fato de que ele, amicus curiae, pode representar, simultaneamente, tanto uma maneira de aperfeiçoamento da prestação da tutela jurisdicional, tornando-a detentora de maior qualidade técnica, quanto uma possibilidade da ampliação do contraditório ${ }^{8}$ processual para que ele se desenvolva de maneira a poder abarcar interesses e/ou direitos de segmentos sociais que, embora não sejam partes propriamente ditas, precisam manifestá-los, pois podem ter

\footnotetext{
${ }^{7}$ YOUNG, Iris Marion. Representação Política, Identidade e Minorias. Revista Lua Nova, n. 67, 2006, p. 170.

8 “O contraditório, com efeito, não é só informação, mas, também, participação em toda a atividade processual, de modo que esta participação seja efetivamente capaz de influir no resultado do processo" (MOREIRA apud ESPINDOLA; SANTOS, 2011, p. 163).
} 
as respectivas esferas jurídicas refletidas ou atingidas, de alguma maneira, quando da finalização da atividade jurisdicional (especialmente em casos complexos em que estejam em discussão paralela a proteção de direitos fundamentais contrapostos a posições majoritárias em termos parlamentares ou executivos).

A qualidade técnica a se incrementar pela atuação dessa figura processual interventiva faz com que a norma constitucional de acesso à Justiça seja atendida de maneira mais coerente, pois não basta que se tenha uma solução judicial para determinada questão problemática que é judicializada, mas, principalmente, uma solução fortemente argumentada e tecnicamente bem estrutura para que a legitimidade da prestação jurisdicional seja sentida e assimilada pelo cidadão que pretende obtê-la.

Igualmente, torna-se viável, atualmente, externar o raciocínio de que o ideal democrático deve ser trabalhado e desenvolvido por todas as esferas de poder estatal e que a atividade processual se responsabiliza por esse desiderato também. Dessa forma, oportunizar ou atribuir ressonância a mecanismos que, verdadeiramente, possam aproximar o poder Judiciário dos cidadãos torna-se uma verdadeira máxima, encontrada ou verificável, por exemplo, na figura interventiva do amicus curiae que, por representar interesses de segmentos sociais, atribui-lhes a chance de serem ouvidas pelo Estado, principalmente envolvendo questões contramajoritárias, muitas vezes destituídas de legitimidade democrática por meios de representação política tradicionais.

Nestes casos, o amicus curiae presta-se à caracterização de verdadeira instância ou locus de atribuição de legitimidade estatal, conforme o pensamento de Müller exposto anteriormente, justamente por funcionar como uma interface entre a sociedade civil e o poder Judiciário do Estado, forçando-o a ampliar o contraditório deliberativo, endoprocessualmente, quando do tratamento de questões que direta ou indiretamente tocam em algum aspecto da vida prática daqueles representados por ele. Acaba por 
atuar, assim, como verdadeira forma de integração democrática, a partir de sua intervenção nas relações processuais, favorecendo, ao mesmo tempo, o aperfeiçoamento da própria noção de acesso à Justiça, norma constitucional que necessariamente tem de ser bem aplicada.

\section{REFERÊNCIAS}

ALEXY, Robert. Teoria discursiva do Direito. Tradução Alexandre Travessoni Gomes Trevisonno. Rio de Janeiro: GEN; Forense Universitária, 2014.

BAZÁN, Víctor. La importancia del amicus curiae en los procesos constitucionales. Revista Jurídica de Derecho Público, Guayaquil, Universidad Católica de Santiago de Guayaquil, Tomo III, 2010.

BOBBIO, Norberto. O futuro da democracia: uma defesa das regras do jogo. 6. ed. Tradução Marco Aurélio Nogueira. São Paulo: Paz e Terra, 2006.

BRASIL. Constituição da República Federativa do Brasil. Brasília, DF: Senado, 1988.

. Senado Federal. Comissão de Juristas Responsável pela Elaboração de Anteprojeto de Código de Processo Civil. Anteprojeto do Novo Código de Processo Civil. Brasília: Senado Federal; Presidência, 2010.

. Superior Tribunal de Justiça (STJ). Agravo regimental nos Embargos ao Recurso Especial (AgRg nos ERESP) no 319.997-SC, Relator: Min. Peçanha Martins, DJ 7/4/2003.

. Lei 13.105 de 16 de março de 2015. Código de Processo Civil. Diário Oficial da União. Brasília, DF, 17 de março de 2015. Disponível em: <http:// www2.camara.leg.br/legin/fed/lei/2015/lei-13105-16-marco-2015-780273-publicacaooriginal-146341-pl.html>. Acesso em: 18 dez. 2016.

BUENO, Cassio Scarpinella. "Amicus curiae: uma homenagem a Athos Gusmão Carneiro”. In: DIDIER JR., Fredie et al. (Coord.). O terceiro no processo civil brasileiro e assuntos correlatos: estudos em homenagem ao professor Athos Gusmão Carneiro. São Paulo: Revista dos Tribunais, 2010. p. 160-167. 
BUENO, Cassio Scarpinella. Quatro perguntas e quatro respostas sobre o Amicus Curiae. In: Revista da Escola Nacional da Magistratura Brasília: Escola Nacional da Magistratura, ano II, n. 5, 2008.

. Amicus Curiae no Projeto de novo Código de Processo Civil. Revista de Informação Legislativa, ano 48 n. 190, Brasília, abr./jun. 2011.

CABRAL, Antônio do Passo. Pelas asas de Hermes: a intervenção do amicus curiae, um terceiro especial. In: Revista de Direito Administrativo, 234: 111141, out./dez. 2003.

CALMON DE PASSOS, José Joaquim. Democracia, participação e processo. In: PELLEGRINI, Ada et al. (Coord.). Participação e processo. São Paulo: Revista dos Tribunais, 1988.

CAMBI, Eduardo. Neoconstitucionalismo e neoprocessualismo: direitos fundamentais, políticas públicas e protagonismo judiciário. 2. ed. São Paulo: RT, 2011.

CAPPELLETTI, Mauro; GARTH, Bryant. Acesso à justiça. Tradução e revisão Ellen Gracie Northfleet. Porto Alegre: Sergio Antônio Fabris Editor, 2002.

CAPPELLETTI, Mauro. O acesso à justiça como programa de reformas e método de pensamento. Tradução Hermes Zaneti Júnior. Revista Brasileira de Direito Processual-RBDPro, Belo Horizonte, ano 16, n. 61, jan./mar. 2008. Disponível em: <http://www.bidforum.com.br/PDI0006.aspx?pdiCntd=52654>. Acesso em: 23 dez. 2016.

CARVALHO, Sabrina Nasser de. Processos coletivos e políticas públicas: mecanismos para a garantia de uma prestação jurisdicional democrática. São Paulo: Contracorrente, 2016.

ESPINDOLA, Ângela Araújo da Silveira; SANTOS, Igor Raatz dos. O processo civil no estado democrático de direito e a releitura das garantias constitucionais: entre a passividade e o protagonismo judicial. Revista NEJ-Eletrônica, vol. 16, n. 2, p. 150-169, maio/ago., 2011.

MÜLLER, Friedrich. Quem é o povo? A questão fundamental da democracia. 7. ed. São Paulo: RT, 2013. 
NUNES, Dierle; BAHIA, Alexandre. Processo, jurisdição e processualismo constitucional democrático na América Latina: alguns apontamentos. Revista Brasileira de Estudos Políticos, Belo Horizonte, n. 101, p. 61-96. jul./dez. 2010. PIOVESAN, Flávia. Direitos humanos globais, justiça internacional e o Brasil. Rev. Fund. Esc. Super. Ministério Público Distrito Federal e Territórios, Brasília, ano 8, v. 15, p. 93-110, 2000.

ROSANVALLON, Pierre. Democracia y Desconfianza. Revista de Estudios Políticos (Nueva Época), Madrid, n. 134, dic. 2006.

SCHUMPETER, Joseph A. Capitalismo, socialismo e democracia. Rio de Janeiro: Zahar, 1984.

WAMBIER, Tereza Arruda Alvim et al. Primeiros comentários ao Novo Código de Processo Civil: artigo por artigo. 1. ed. São Paulo: RT, 2015.

YOUNG, Iris Marion. Representação política, identidade e minorias. Revista Lua Nova, n. 67, 2006. 